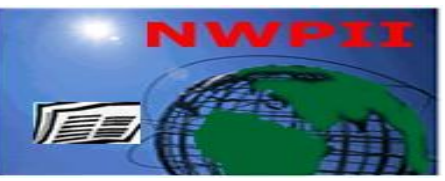

American Journal of Biomedical Sciences

ISSN: 1937-9080

nwpii.com/ajbms

\title{
Does Inhibition of Arginase and Advanced Glycation End Products Provide a Protection Against Experimentally Induced Diabetic Nephropathy?
}

\begin{abstract}
Noha I. Hussien
Department of Physiology, Faculty of Medicine, Benha University, Egypt

Corresponding Author

Noha I. Hussien M.D.

Department of Physiology

Faculty of Medicine

Benha University

Egypt

Received: 30 September 2015; $\mid$ Revised: 29 November 2015; $\mid$ Accepted: 11 December 2015

Abstract

Diabetic nephropathy (DN) occurs in approximately one-third of all people with diabetes and is the leading cause of renal failure in developed and developing countries. The aim of the current study was to assess the possible protective effects of arginase and advanced glycation end (AGE) product inhibitors against DN and the possible underlying mechanisms. The present study was conducted on 40 male albino rats that were grouped into five groups of 8 rats each. Group I: control group that received single intraperitoneal (I.P.) injection of citrate Buffer. Group II: DN group that induced by administration of streptozotocin (STZ). Group III and Group IV have DN treated with L-citrulline an arginase inhibitor, and pyridoxamine (PM) an AGE inhibitor respectively. Group V: rats with DN treated with both L-citrulline and PM daily for 6 weeks. At the end of the treatment period blood glucose, urea, serum creatinine and urinary albumin excretion rate were measured. Renal tissue levels of AGEs, arginase activity, TGF- $\beta 1$, malondialdehyde (MDA), reduced glutathione (GSH) and nitrate were assessed. DN group showed significant increase in albuminuria, blood glucose, urea, serum creatinine as well as renal AGEs, arginase activity, MDA and TGF- $\beta 1$ concentrations, together with a significant decrease in renal NO and GSH. Administration of either L-citrulline or PM resulted in a significant amelioration of the above mentioned parameters. And their combination leads to more protective effect. In conclusion, inhibition of both arginase and AGEs could represent therapeutic options for patients with DN.
\end{abstract}

Keywords: Diabetic Nephropathy; advanced glycation end product; arginase activity; L-citrulline; pyridoxamine.

\section{Introduction}

The number of people living with diabetes in the world is expected to double between 2000 and 2030 [1]. This global increase in the prevalence of diabetes will lead to acceleration of micro- and macrovascular complications of diabetes. The important causative factor in the 
development of complications in patients with diabetes is hyperglycemia. DN is the most common microvascular complication of diabetes mellitus. It is a leading cause of end-stage renal disease and a contributor to significant morbidity and mortality in patients with diabetes [2].

Diabetic complications appear to be multifactorial in origin as several factors are incriminated in the genesis and progression of DN: these include hemodynamic factors as endothelial cell dysfunction and metabolic factors as advanced glycation end products (AGEs), protein kinase $\mathrm{C}$, the renin-angiotensin system, transforming growth factor- $\beta 1$, etc. [3].

Arginase is a hydrolytic enzyme responsible for converting L-arginine to urea and L-ornithine. Mammalian arginases exist in two distinct isoforms (type I and type II) which are encoded by separate genes, have specific subcellular localization and tissue distribution. Arginase $\mathrm{I}$ is a cytosolic enzyme located primarily in the liver, whereas arginase II is located within the mitochondrion and is expressed at high levels in the kidneys [4].

Endothelial cell dysfunction is a central pathophysiological mechanism that contributes to diabetes and DN. Dramatic alterations in arginine metabolism occur in endothelial injury due to changes in the activity and/or expression of nitric oxide synthases (NOS) and arginases. Arginase-2 is constitutively expressed and also inducible in endothelial cells as well as in kidney cells and, when elevated, can inhibit NOS activity/expression and induce endothelial NOS uncoupling, thus reducing NO bioavailability and inhibiting the NO/cGMP pathway. We hypothesize that arginases promote the development and progression of diabetic kidney damage [5].

L-citrulline is amino acid that naturally produced by the body. It is found in some foods like watermelons. It is the natural precursor of Larginine, substrate for NOS in the production of NO. L-citrulline is not metabolized in the intestine or liver and inhibits arginase activity. Lcitrulline entering the kidney, vascular endothelium and other tissues can be readily converted to L-arginine, thus raising plasma and tissue levels of L-arginine and enhancing NO production. Supplemental L-citrulline has promise as a therapeutic adjunct in disease states associated with increased arginase activity [6].

Much attention has been paid in the recent years to the non-enzymatic glycation involves the reaction of the carbonyl group of sugar aldehydes with the N-terminus of free amino groups of proteins, resulting in the formation glycated proteins, that may then react with other proteins, lipids or DNA resulting in irreversible cross linking and the formation of AGEs. Although AGEs formation happens as a result of normal aging, it occurs at an accelerated rate in diseases as diabetes mellitus and DN as a result of chronic hyperglycemia and increased oxidative stress [7].

Pyridoxamine (PM) is one form of vitamin B6 that prevents irreversible protein glycation, thereby reduces the formation of advanced glycation end products (AGEs), so it may reduce various diabetic complications [8].

The potential interactive effects of Lcitrulline as an arginase inhibitor and PM as an AGEs inhibitor in the treatment of DN have not been investigated. Therefore, this study was designed to determine the effects of combined Lcitrulline and PM treatments on DN and the possible underlying mechanisms.

\section{Material and Method}

\subsection{Animals}

All of the animals were approved by the Ethical Committee of the Faculty of Medicine, Benha University, Egypt. This study was conducted on 40, 6-8 weeks old, adult albino male rats each weighing between 180 and 200 gm. Animals was housed in the animal laboratory at the medical research center at Benha faculty of medicine. They were allowed free access to water and standard diet.

\subsection{Experimental protocol}

The animals were randomly divided into five groups, each of 8 animals as follow:

Group I (Normal control group): Control group injected with a single dose of $1 \mathrm{ml}$ citrate buffer, IP and injected with $1 \mathrm{ml}$ saline daily for 6 weeks. 
Group II (DN group): Diabetes was induced by a single intraperitoneal injection of $55 \mathrm{mg} / \mathrm{kg}$ STZ (Sigma-Aldrich Chemical Co.) dissolved in citrate buffer (0.1 mol/l, $\mathrm{pH}: 4.6)$ [9].

Group III (DN-L-citrulline group): received L-citrulline $(50 \mathrm{mg} / \mathrm{kg})$ dissolved in distilled water by orogastric gavage. It was administrated once the rats became diabetic for 6 weeks [10, $11]$.

Group IV (DN-PM group): received PM (60 $\mathrm{mg} / \mathrm{kg}$ ) dissolved in distilled water by IP injection. It was administrated once the rats became diabetic for 6 weeks [12].

Group V (DN- L-citrulline-PM group): received combination of L-citrulline and PM once the rats became diabetic for 6 weeks.

\subsection{Induction and diagnosis of diabetes mellitus}

Diabetes was induced by intraperitoneal (IP) injection of a single dose of STZ $(100 \mathrm{mg} / \mathrm{kg}$ in freshly prepared citrate buffer $\mathrm{pH}$ 4.5). Diabetes was verified 72 hours later by measuring blood glucose levels (after an overnight fasting) by tail blood glucose measurement with the use of glucose oxidase reagent strips. Rats having blood glucose level of $>250 \mathrm{mg} / \mathrm{dl}$ were considered to be diabetic [9].

To maintain body weight and limit hyperglycemia, all diabetic animals were treated with 3IU of ultralente insulin, three times per week to maintain glycemic control as the rats gained weight. At the end of the experiment, the fasted rats were anaesthetized by injection of sodium thiopental and blood samples were collected from abdominal aorta and processed for determination of blood glucose that estimated by the glucose oxidase-peroxidase method (GODPOD kit), urea and serum creatinine were assessed using the Jaffe' picric acid procedure with Sigma kit \#555-A (Sigma-Aldrich Chemical Co.).

Urinary albumin was measured by means of quantitative reaction using a sigma diagnostic kit. Then rats were sacrificed and their kidneys were rapidly collected and divided into 2 parts. One part was put in $10 \%$ formalin for histopathological examination. The second part was homogenized and the homogenate was kept at $-80^{\circ} \mathrm{C}$ and used for the measurement of: Arginase activity, that was measured spectrophotometrically by arginase activity colorimetric kit from (Sigma-St. Louis, MO) [9]. AGE concentration in renal homogenate was determined with AGE ELISA kit, Roche Diagnostics (Mannheim, Germany) [13]. Renal level of TGF- $\beta$ was determined using an enzymelinked immunosorbent assay (ELISA technique) [14]. Nitrate the metabolic end-product of NO, measured in renal tissue according to the method described by Bories and Bories (1995) [15]. Lipid peroxidation in renal tissues was estimated by the determination of thiobarbituric acid reactive substances content that was evaluated as MDA in renal homogenate using a standard kit purchased from Biodiagnostic (Egypt) [16]. Renal GSH content was determined using a commercial kit (Biodiagnostic, Egypt) [17].

\subsection{Statistical analysis}

The results were expressed as mean values \pm S.D. The data were analyzed by one-way analysis of variance (ANOVA) followed by TukeyKramer multiple comparisons test as post hoc test. $\mathrm{P}<0.05$ was considered statistically significant.

\section{Results}

\subsection{Mortality rate}

Only one rat died in the DN group with a mortality rate of $12.5 \%$.

\subsection{Biochemical results}

STZ administration resulted in a significant $(\mathrm{p}<0.001)$ increase in blood glucose, urea and serum creatinine as well as significant $(\mathrm{p}<0.001)$ increase in renal arginase activity, AGEs, MDA and TGF- $\beta 1$ concentrations with significant reduction in nitrate and GSH concentration in DN group when compared with control group. Treatment with L-citrulline resulted in a significant $(\mathrm{p}<0.001)$ decrease in blood urea and serum creatinine as well as renal arginase activity, AGEs and MDA concentrations together with a significant $(p<0.001)$ increase in nitrate and GSH concentration in (DN- L-citrulline group) as compared to (DN group). Treatment with PM resulted in a significant $(p<0.001)$ decrease in 
blood glucose, urea and serum creatinine as well as renal AGEs, MDA and TGF- $\beta 1$ concentrations with a significant $(\mathrm{p}<0.001)$ increase in $\mathrm{GSH}$ concentration in (DN- PM Group) as compared to (DN group). There was significant decrease in all parameters in (DN- L-citrulline-PM group) when compared with (DN- L-citrulline group) and (DN- PM Group) indicating that combination of treatment leads to more protective effect than each one alone. By comparing between (DN- L- citrulline group) and (DN- PM Group) there was significant improvement of blood urea $(\mathrm{p}<0.001)$, serum creatinine $(\mathrm{p}<0.05)$, renal arginase $(\mathrm{p}<0.001)$ and renal nitrate $(\mathrm{p}<0.001)$ in $(\mathrm{DN}-\mathrm{L}-$ citrulline group) and significant improvement in blood glucose $(\mathrm{p}<0.001)$, renal AGE $(\mathrm{p}<0.001)$ and renal TGF- $\beta 1(\mathrm{p}<0.001)$ in (DN- PM Group) indicating that their nephroprotective effects occurs by different mechanisms (table 1).

Table 1. Comparison between mean \pm SD of all parameters in all groups

\begin{tabular}{|c|c|c|c|c|c|}
\hline $\begin{array}{ll}\text { proup } & \text { groumeters }\end{array}$ & $\begin{array}{l}\text { Group I } \\
n=8\end{array}$ & $\begin{array}{l}\text { Group II } \\
n=7\end{array}$ & $\begin{array}{l}\text { Group III } \\
n=8\end{array}$ & $\begin{array}{l}\text { Group IV } \\
n=8\end{array}$ & $\begin{array}{l}\text { Group V } \\
n=8\end{array}$ \\
\hline $\begin{array}{l}\text { Blood glucose } \\
\text { (mg/dl) }\end{array}$ & $100 \pm 2.2$ & $373.7 \pm 12.5^{\mathrm{a}}$ & $356.9 \pm 20.6$ & $279.8 \pm 6.5^{b c}$ & $118.4 \pm 6.5^{b c d}$ \\
\hline $\begin{array}{l}\text { Blood urea } \\
\text { (mg/dl) }\end{array}$ & $12.2 \pm 0.53$ & $21.7 \pm 1.5^{\mathrm{a}}$ & $15.9 \pm 1.2^{b}$ & $18 \pm 0.83^{b c}$ & $13 \pm 0.76^{\mathrm{bcd}}$ \\
\hline $\begin{array}{l}\text { Serum creatinine } \\
\text { (mg/dl) }\end{array}$ & $0.4 \pm 0.01$ & $2.5 \pm 0.17^{\mathrm{a}}$ & $1.5 \pm 0.08^{b}$ & $1.8 \pm 0.34^{b} *$ & $0.83 \pm 0.1^{\mathrm{bcd}}$ \\
\hline $\begin{array}{l}\text { Urinary albumin } \\
\text { excretion rate }(\mathrm{mg} / 24 \mathrm{~h})\end{array}$ & $0.4 \pm 0.03$ & $3.3 \pm 0.2^{\mathrm{a}}$ & $1.06 \pm 0.2^{\mathrm{b}}$ & $1.1 \pm 0.19^{b}$ & $0.5 \pm 0.1^{\mathrm{bcd}}$ \\
\hline $\begin{array}{l}\text { Renal arginase } \\
(\mathrm{nmol} / \mathrm{min} / \mathrm{mg})\end{array}$ & $4.05 \pm 0.45$ & $10.3 \pm 1.1^{\mathrm{a}}$ & $6.6 \pm 0.84^{\mathrm{bd}}$ & $8.2 \pm 0.36^{b}$ & $5.3 \pm 0.4^{\mathrm{bcd}}$ \\
\hline 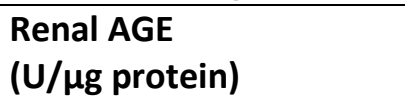 & $0.09 \pm 0.02$ & $0.47 \pm 0.06^{\mathrm{a}}$ & $0.2 \pm 0.02^{b}$ & $0.12 \pm 0.01^{b c}$ & $0.09 \pm 0.04^{\mathrm{bc} \&}$ \\
\hline $\begin{array}{l}\text { Renal TGF- } \beta 1 \\
\text { (ng/ml) }\end{array}$ & $398.8 \pm 7.7$ & $997 \pm 9.3^{a}$ & $985.8 \pm 34.8$ & $545 \pm 8.9^{b c}$ & $427 \pm 7.4^{\mathrm{bcd}}$ \\
\hline $\begin{array}{l}\text { Renal nitrate } \\
\text { (mM /mg protein) }\end{array}$ & $31.3 \pm 1.8$ & $16 \pm 1.4^{\mathrm{a}}$ & $30.8 \pm 3.1^{\mathrm{bd}}$ & $15.9+1.2$ & $30.3+1.7^{b d}$ \\
\hline $\begin{array}{l}\text { Reduced GSH } \\
\text { (mg protein) }\end{array}$ & $6.3 \pm 0.87$ & $2.07 \pm 0.2^{\mathrm{a}}$ & $4.7 \pm 0.8^{b}$ & $4.8 \pm 0.52^{b}$ & $6.2 \pm 0.2^{\mathrm{bcd}}$ \\
\hline $\begin{array}{l}\text { MDA } \\
\text { (nmol/g tissue) }\end{array}$ & $7.08 \pm 0.2$ & $13.96 \pm 0.2^{\mathrm{a}}$ & $10.6 \pm 0.5^{b}$ & $10.3 \pm 0.45^{b}$ & $7.6 \pm 0.9^{b c d}$ \\
\hline
\end{tabular}

a: Statistically significant compared to the corresponding value in group $(I)(p<0.001)$.

$b$ : Statistically significant compared to the corresponding value in group (II) $(p<0.001)$.

c: Statistically significant compared to the corresponding value in group $(I I I)(p<0.001)$.

$d$ : Statistically significant compared to the corresponding value in group $(I V)(p<0.001)$.

*: Statistically significant compared to the corresponding value in group (III) $(p<0.05)$.

$\&$ : Statistically significant compared to the corresponding value in group $(I V)(p<0.05)$.

\subsection{Histopathological finding}

Group I: Showed normal appearance of the glomeruli \& tubules fig. 1 (A). Group II: Showed severe diffuse glomerulosclerosis, cellular infiltration, interstitial fibrosis, tubular dilatation and mesangial expansion fig. 1 (B). Group III: Showed improvement of both tubular dilatation and mesangial expansion and decrease of interstitial cellular infiltration fig. 1 (C). Group IV: Showed improvement of glomerulosclerosis but there is tubular atrophy \& dilatation fig. 1 (D). Group V: Showed marked improvement of both tubular dilatation and mesangial expansion and decrease of interstitial cellular infiltration fig. 1 (E). 
Fig 1(A,B,C,D,E): Histopathological finding
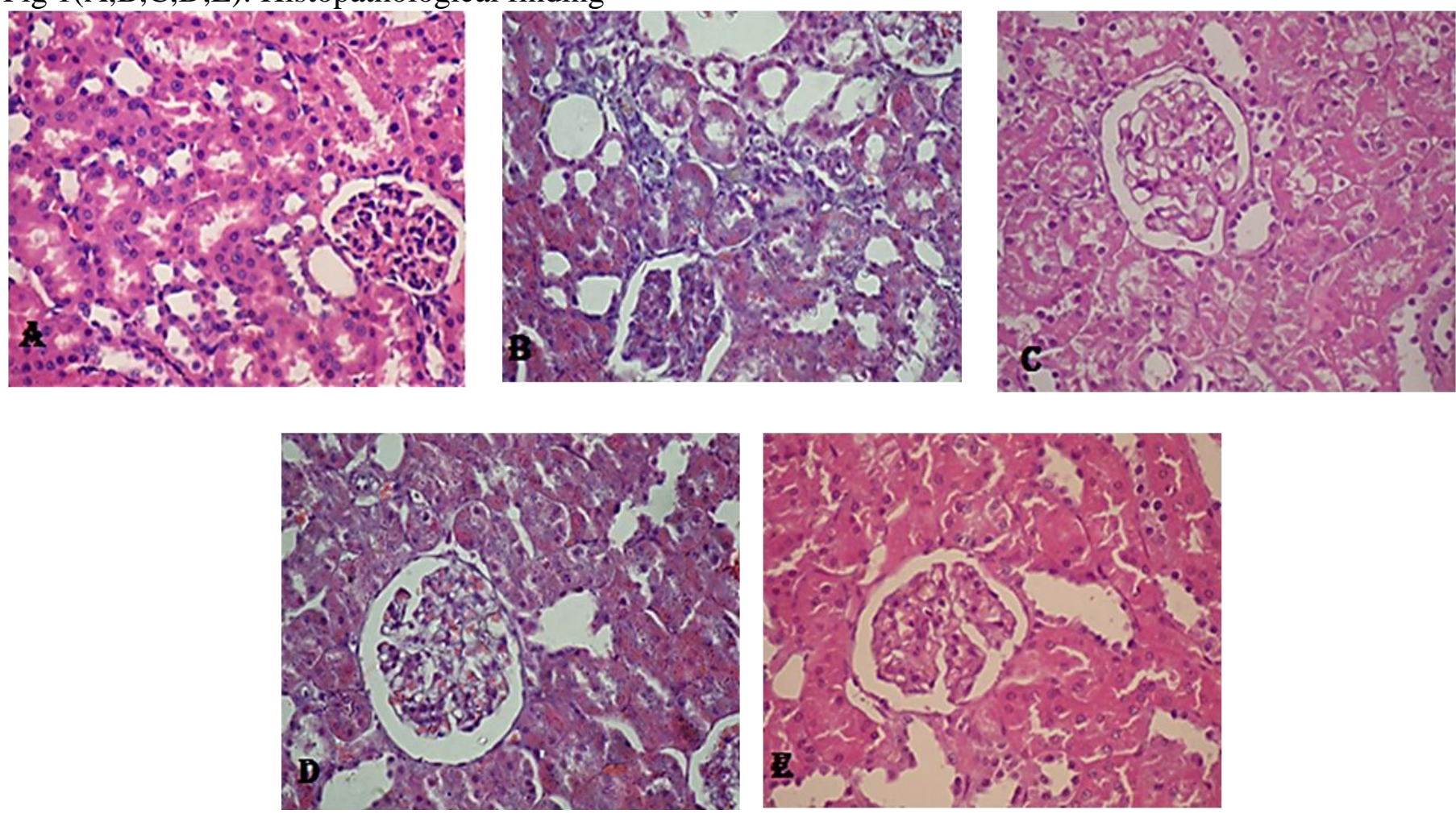

Figure 1. (A): Cut section of rat kidney of control group showing normal glomeruli and tubules. Figure1 (B): Cut section of renal tissues of diabetic non treated rats showing marked lobulation of glomeruli with dense interstitial fibrosis. Figure 1 (C): Cut section of renal tissues of L-citrruline treated rats showing mild affection of glomeruli and mild tubular dilatation. Figure 1 (D): Cut section of renal tissues of PM treated rats showing mild affection of glomeruli and mild tubular dilatation. Figure 1 (E): Cut section of rat kidney of combined L-citrruline and PM treated group showing restoration of the tubular and glomerular structure to a very large extent (H \& E x 40).

\section{Discussion}

Although pathogenesis of DN is not entirely elucidated, it is evident from numerous studies that hemodynamic as well as metabolic factors play an important role in its development. DN is thus a result of, interplay between those pathophysiologic factors although the basal pathogenic factor is of course hyperglycaemia [18].

So in this study we examined the inhibition of arginase activity as a hemodynamic factor and the inhibition of $\mathrm{AGE}$ as a metabolic factor in ameliorating $\mathrm{DN}$ and the possible underlying mechanisms.

In this study Single injection of STZ successfully induced diabetic nephropathy as evidenced biochemically by significant increase of blood glucose, urea, serum creatinine and urine protein. This confirmed histopathologically by inflammatory cell infiltration, fibrosis and diffuse glomerular sclerotic lesion, these results were in agreement with [19].

Diabetic urinary albumin leakage involves several mechanisms, including proximal tubular injury and disruption of the glomerular barrier. The relevance of the glomerular endothelium in the maintenance of barrier function has only been recently recognized. While endothelial NO generation contributes to endothelial glycocalyx and barrier preservation, an increase in the ROS/NO ratio causes disruption of the glycocalyx, resulting in enhanced albumin permeability [20]. This can be explained in this study by increasing oxidative stress evidenced by increase in MDA and reduction of GSH. With 
decreasing in NO level in renal tissue of DN group when compared with the control group.

Also DN group showed significant increase in arginase activity supporting the notion that it might play a role in the pathogenesis of DN. These results were in agreement with Previous studies, which have shown that vascular dysfunction in rodent models of diabetes [21,24] or diabetic patients [22] is associated with increased arginase-1 [22,24] or arginase-2 [21] expression and that vascular function is normalized by inhibition of arginase activity or genetic ablation of arginase-2 expression [21,23].

Alteration in endothelial function is a common underlying event for hemodynamic abnormalities observed in patients with diabetes and DN. Endothelial dysfunction, characterized by reduced bioavailability of NO and increased oxidative stress, is a hallmark of diabetes and DN [25]. NO is produced from arginine by NOS. Under conditions of low arginine level or hyperglycemia, endothelial NOS can become uncoupled, producing reactive oxygen species instead of NO. When, arginase-2 elevated it can inhibits NOS activity and expression and thus induces endothelial NOS uncoupling, thereby reducing NO bioavailability and inhibiting the NO/cGMP pathway as well as increasing oxidative stress [26].

L-citrulline was chosen as arginase inhibitor based upon its reported arginase inhibiting activity by other studies $[27,28]$ and confirmed in this study by decreasing arginase activity in group III when compared with DN group.

Treatment with L-citrulline leads to significant improvement in renal function in spite of havening no effect on blood glucose level. This can be explained by improving the hemodynamic factors of DN by decreasing arginase activity and increasing NO level in renal tissue in addition to its antioxidant effect. These results were in agreement with that of other studies $[29,30]$.

Induction of $\mathrm{DN}$ in this study leads to significant increase in TGF- $\beta$ in renal tissue of DN group when compared with control group indicating that it may be a signalling factor for progression of DN. This finding is the same of Many studies reported that high glucose stimulated collagen production by TGF- $\beta$, a profibrotic cytokines [31]. TGF- $\beta$ expression is mainly increased in mesangial cells of diabetic human glomeruli, but increased TGF- $\beta$ expression in glomerular endothelial cells has also been reported [32].

Treatment with L-citrulline leads to nonsignificant effect on TGF- $\beta$ level in renal tissue indicating that its nephroprotective effect is not mediated by change in this factor.

Induction of DN in this study leads to significant increase in AGEs in renal tissue of DN group when compared with control group and this finding is the same of other studies [33, 34] which, explain that increased protein glycation and AGEs formation as a consequence of hyperglycemia are mostly implicated and are responsible for diabetic complications due to their ability to alter enzymatic activity, decrease ligand binding, modify protein half-life and alter immunogenicity.

PM was chosen in this study as AGEs inhibitor as it is the most potent natural substance for inhibiting AGEs formation [35]. As well as another clinical study has demonstrated increased degradation of vitamin B6 in diabetic patients [36].

Treatment with $\mathrm{PM}$ in (DN+ PM group) leads to significant improvement of renal function with significant decrease in blood glucose, renal AGEs, MDA, TGF- $\beta$ and increase in GSH levels when compared with DN group. This can be explained by other studies that PM can inhibit three processes critical in development of diabetic complications. Firstly, PM can sequester glucose and reactive products of glucose and lipid degradation, thus inhibiting formation of advanced glycation and advanced lipoxidation end products". Secondly, PM can scavenge catalytic metal ions, thus inhibiting toxic oxidative reactions; and thirdly, PM can react with free oxygen radicals, thus preventing them from damaging biologically important macromolecules such as proteins and DNA [33,37]. PM can scavenge toxic free radicals being produced in excess by high glucose and ketone levels in diabetic patients, and pyridoxamine can increase the utilization of glucose. pyridoxamine utilizes a two-pronged 
approach: it causes glucose to be metabolized more quickly, effectively reducing high glucose levels, while it consumes toxic free radicals produced by high levels of glucose and ketones (chemicals produced when fat is burned for energy) accompanying diabetes [37].

Regarding TGF- $\beta$, it is an important mediator for the pathogenesis of $\mathrm{DN}$ and may inhibit matrix degradation, upregulate adhesion molecules and enhance chemoattraction. The increase observed in the TGF- $\beta$ in renal tissue is mostly attributed to hyperglycemia and AGEs effects. TGF- $\beta$ is a powerful stimulator for the synthesis, deposition of collagen and other extra cellular matrix (ECM) proteins. It may account even partially for the thickening of the basement membrane in DN [38].

TGF- $\beta$ is considered the pivotal cytokine in mediating collagen deposition in the kidney. Not only does it stimulate gene expression of various matrix proteins but it influences the matrix degrading enzyme pathways by inhibiting the synthesis of matrix metalloproteinases and stimulating the production of metalloproteinase inhibitors. In vitro studies have shown that a range of stimuli increase TGF- $\beta$ expression. These include hyperglycemia, AGEs, stretch, lipids and various products of oxidative stress, all factors relevant to the progression of DN [39].

In DN group all biochemical abnormalities have been linked to various structural aspects of DN, including glomerular basement membrane thickening, mesangial expansion, glomerulosclerosis, and tubulointerstitial fibrosis. Both L-citrulline and PM shows improvement of renal histology and their combination shows the most improvement. These results were in agreement with Vivian Soetikno et al.[40], who explained that AGEs accumulate in glomerular basement membrane, mesangial cells, endothelial cells, and podocytes of the patients with DN. Their receptors (RAGE) are expressed by mesangial cells, tubular cells, podocytes and endothelial cells. Furthermore, the AGEs-RAGE interaction is considered as a causative factor for DN through activating a series of intracellular signal-cascade pathways which might induce the generation of further signalling factors, such as (TGF- $\beta$ ). This signalling factor might cause mesangial expansion, glomerulosclerosis, glomerular hyper permeability, and tubular inflammation, etc. AGEs have, therefore, been regarded as a focal target to inhibit the irreversible deterioration of $\mathrm{DN}$.

Treatment with PM leads to non-significant effect on arginase activity and NO level in renal tissue indicating that its nephroprotective effect is not mediated by change in these factors.

In the current study the results show that arginase inhibition has significant protective effect on blood urea and serum creatinine more than AGE inhibitors indicating that the improvement in the hemodynamic factors leads to more protective effect than the improvement in the metabolic factors leading to DN.

To the best of my knowledge, this is the first report that analyzes the effect of combination of L-citrulline with PM on a DN model. The current study revealed that their combination leads to more significant protective effect on DN than each one alone. This may be due inhibition of both the metabolic and hemodynamic factors leading to DN. And so synergistic interactions among the various pathogenic pathways leading to diabetic complications is critical in order to develop interventions that confer optimal endorgan protection.

\section{Conclusion}

This study opens new areas of therapy and provides new modalities for the management of DN. Targeting arginase activity and AGEs could represent therapeutic options for patients at risk of developing DN.

\section{References}

1. Shaw J.E., Sicree R.A., Zimmet P.Z. "Global estimates of the prevalence of diabetes for 2010 and 2030," Diabetes Research and Clinical Practice 2010;87, 1:4-14. doi: 10.1016/j.diabres.2009.10.007.

2. Mima A. "Inflammation and oxidative stress in diabetic nephropathy: new insights on its inhibition as new therapeutic targets," Journal of Diabetes Research, vol. 2013, 
Article ID 248563, 8 pages, 2013. DOI: $10.1155 / 2013 / 248563$

3. Shah IM, Mackay SP, McKay GA. Therapeutic strategies in the treatment of diabetic nephropathy - a translational medicine approach. Curr Med Chem. 2009;16:9971016. DOI: $10.2174 / 092986709787581897$

4. Teddy Bagnost, Ling Ma, Rafaela F. da Silva,Rana Rezakhaniha, Christophe Houdayer, Nikos Stergiopulos, Claire Andre', Yves Guillaume, Alain Berthelot, $\mathrm{Ce}^{\prime}$ line Demougeot. Cardiovascular effects of arginase inhibition in spontaneously hypertensive rats with fully developed hypertension. Cardiovascular Research 2010; 87:569- 577. DOI: $10.1093 / \mathrm{cvr} / \mathrm{cvq} 081$

5. You H, Gao T, Cooper TK, Morris SM Jr, Awad AS. Arginase inhibition mediates renal tissue protection in diabetic nephropathy by a nitric oxide synthase 3-dependent mechanism. Kidney Int. 2013 Dec; 84(6):1189-97. DOI: 10.1038/ki.2013.215

6. Lu Zhou, Chuan-Bo Sun, Chao Liu, Yue Fan, Hong-Yi Zhu, Xiao-Wei Wu, Liang $\mathrm{Hu}$, Qing-Ping Li. Upregulation of arginase activity contributes to intracellular ROS production induced by high glucose in $\mathrm{H} 9 \mathrm{c} 2$ cells. Int J Clin Exp Pathol 2015;8(3):27282736. PMCID: PMC4440087

7. Sourris KC, Forbes JM . Interactions between advanced glycation end-products (AGE) and their receptors in the development and progression of diabetic nephropathy-are these receptors valid therapeutic targets. Curr Drug Targets 2009;10: 42-50. DOI: $\underline{10.2174 / 138945009787122905}$

8. Voziyan PA, Hudson BG . "Pyridoxamine: the many virtues of a maillard reaction inhibitor". Ann. N. Y. Acad. Sci. 2005.1043 (1): 807-16. DOI: 10.1196/annals.1333.093

9. Xian-Wei Li, Yan Liu, Wei Hao, Jie-Ren Yang. Sequoyitol ameliorates diabetic nephropathy in diabetic rats induced with a high-fat diet and a low dose of streptozotocin. Canadian Journal of Physiology and Pharmacology, 2014, 92, 5 : 405-417. DOI: 10.1139/cjpp-2013-0307.

10. Hany M El-Bassossy, Rania El-Fawal, Ahmed Fahmy and Malcolm L Watson.
Arginase inhibition alleviates hypertension in the metabolic syndrome British Journal of Pharmacology. 2013; 169: 693-703. DOI: $10.1111 / \mathrm{bph} .12144$

11. Romero MJ, Platt DH, Tawfik HE, Labazi M, El-Remessy AB, Bartoli M . Diabetesinduced coronary vascular dysfunction involves increased arginase activity. Circ Res2008; 102: 95-102. doi: 10.1161/CIRCRESAHA.107.155028

12. Elizabeth A. Muellenbach, Cody J. Diehl, Mary K. Teachey, Katherine A. Lindborg, Tara L. Archuleta, Nicholas B. Harrell, Gaby Andersen, Veronika Somoza, Oliver Hasselwander, Markus Matuschek, Erik J. Henriksen. Interactions of the advanced glycation end product inhibitor pyridoxamine and the antioxidant $\alpha$-lipoic acid on insulin resistance in the obese Zucker rat metabolism clinical and experimental. 2008, 57, $\quad 10, \quad 1465-1472 . \quad$ DOI: 10.1016/j.metabol.2008.05.018

13. Charan S, Palmer K, Chester P, Mire-Sluis AR, Meager A. Transforming growth factorbeta induced by live or ultraviolet-inactivated equid herpes virus type- 1 mediates immunosuppression in the horse. Immunology1997;90:586-591.

14. Münch G, Keis R, Wessels A, Riederer P, Bahner $U$. Determination of advanced glycation end products in serum by fluorescence spectroscopy and competitive ELISA. Eur J Clin Chem Clin Biochem .1997;35: 669-677. 1997 by Walter de Gruyter · Berlin · New York

15. Bories P.N., and Bories C.: Nitrate determination in biological fluids by an enzymatic one-step assay with nitrate reductase. Clin. Chem 1995; 41:904-907. 1995 The American Association for Clinical Chemistry

16. The susceptibility to autoxidation of human red cell lipids in health and disease Stocks J, Offerman EL, Modell CB, Dormandy TL Br J Haematol. 1972; 23(6):713-24. DOI: 10.1111/j.1365-2141.1972.tb03486.x

17. D.E. Paglia, W.E. Valentine Studies on quantitative and qualitative characterization 
of erythrocyte glutathione peroxidase J. Lab. Clin. Med.1967;70,158-169.

18. J. M. Forbes, K. Fukami, and M. E. Cooper, "Diabetic nephropathy: where hemodynamics meets metabolism," Experimental and Clinical Endocrinology \& Diabetes.2007; 115, 2: 69-84. DOI: 10.1055/s-2007-949721

19. Hanning You, Ting Gao, Timothy K Cooper, Sidney M Morris and Alaa S Awad. Arginase inhibition mediates renal tissue protection in diabetic nephropathy by a nitric oxide synthase 3-dependent mechanism Kidney International. 2013;84: 1189-1197. doi:10.1038/ki.2013.215

20. Singh A, Fridén V, Dasgupta I, Foster RR, Welsh GI, Tooke JE, Haraldsson B, Mathieson PW, Satchell SC. High glucose causes dysfunction of the human glomerular endothelial glycocalyx.Am J Physiol Renal Physiol. 2011 Jan; 300(1):F40-8. DOI: 10.1152/ajprenal.00103.2010

21. Grönros J, Jung C, Lundberg JO, Cerrato R, Ostenson CG, Pernow J. Arginase inhibition restores in vivo coronary microvascular function in type 2 diabetic rats. Am J Physiol Heart Circ Physiol 2011; 300: 1174-1181 . DOI: 10.1152/ajpheart.00560.2010

22. Beleznai T, Feher A, Spielvogel D, Lansman SL, Bagi Z. Arginase 1 contributes to diminished coronary arteriolar dilation in patients with diabetes. Am J Physiol Heart Circ Physiol 2011;300: 777-783. DOI: 10.1152/ajpheart.00831.2010

23. Toque HA, Tostes RC, Yao L, Xu Z, Webb RC, Caldwell RB, Caldwell RW. Arginase II deletion increases corpora cavernosa relaxation in diabetic mice. J Sex Med 2011;8:722-733. $\quad$ DOI: $10.1111 / \mathrm{j} .1743-$ 6109.2010.02098.x

24. Romero MJ, Platt DH, Tawfik HE, et al. Diabetes-induced coronary vascular dysfunction involves increased arginase activity. Circ Res 2008;102:95-102. DOI: 10.1161/CIRCRESAHA.107.155028

25. Sidney M. Morris Jr., Ting Gao, Timothy K. Cooper, Diane Kepka-Lenhart, Alaa S. Awad. Arginase-2 Mediates Diabetic Renal Injury
Diabetes November 2011; 60 : 11 30153022. DOI: $10.2337 / \mathrm{db} 11-0901$

26. Hanning You, Ting Gao, Timothy K. Cooper, Sidney M. Morris Jr., Alaa S. Awad .Arginase Inhibition: A New Treatment for Preventing Progression of Established Diabetic Nephropathy American Journal of Physiology - Renal Physiology Published 3 June 2015 Vol. no. , DOI: 10.1152/ajprenal.00137.2015.

27. Romero MJ, Platt DH, Tawfik HE, Labazi M, El-Remessy AB, Bartoli M . Diabetesinduced coronary vascular dysfunction involves increased arginase activity. Circ Res 102: 95-102.

28. Hany M El-Bassossy,, Rania El-Fawal, Ahmed Fahmy, Malcolm L Watson. Arginase inhibition alleviates hypertension in the metabolic syndrome British Journal of Pharmacology .2013; 169 693-703. doi: 10.1161/CIRCRESAHA.107.155028

29. Maritza J. Romero, Lin Yao,1 Supriya Sridhar, Anil Bhatta, Huijuan Dou, Ganesan Ramesh, Michael W. Brands, David M. Pollock, Ruth B. Caldwell, Stephen D. Cederbaum, C. Alvin Head, Zsolt Bagi, Rudolf Lucas, Robert W. Caldwell. 1Citrulline Protects from Kidney Damage in Type 1 Diabetic Mice. Front Immunol. 2013; 4: 480. DOI: 10.3389/fimmu.2013.00480

30. Patrik Persson, Angelica Fasching2, Tom Teerlink3, Peter Hansell2 and Fredrik Palm. L-citrulline, but not L-arginine, prevents diabetes-induced glomerular hyperfiltration and proteinuria. The FASEB Journal2014; vol. 28 no. 1 Supplement 689.12. DOI: 10.1096/fj.1530-6860

31. Y. Sasai, K. Iwakawa, K. Yanagida . "Advanced glycation endproducts stimulate renal epithelial cells to release chemokines that recruit macrophages, leading to renal fibrosis," Bioscience, Biotechnology and Biochemistry2012; 76, 9: 1741-1745. DOI: $10.1155 / 2014 / 968681$

32. C. H. Chou, L. Y. Chuang, C. Y. Lu, and J. Y. Guh, "Interaction between TGF- $\beta$ and ACE2-Ang-(1-7)-Mas pathway in high glucose-cultured NRK-52E cells," Molecular 
and Cellular Endocrinology .2013;366, 1: 21-30. doi: 10.1016/j.mce.2012.11.004.

33. Mohamed M Elseweidy, Sahar E Elswefy, Nahla N Younis and Mohamed S Zaghloul cytokines in experimental diabetic nephropathy Pyridoxamine, an inhibitor of protein glycation, in relation to microalbuminuria and proinflammatory. Exp Biol Med $2013 \quad$;238: 881. doi: $10.1177 / 1535370213494644$

34.Lewis EJ, Greene T, Spitalewiz S, Blumenthal S, Berl T, Hunsicker LG, Pohl MA, Rohde RD, Raz I, Yerushalmy Y, Yagil Y, Herskovits T, Atkins RC, Reutens AT, Packham DK, Lewis JB. Pyridorin in type 2 diabetic nephropathy. J Am Soc Nephrol 2012;23:131-6. doi: 10.1681/ASN.2011030272.

35. Perricone N. Ageless Face, Ageless Mind. New York, New York: Ballantine Books; 2007.

36. Adaikalakoteswari A, Rabbani N, Waspadji S, Tjokroprawiro A, Kariadi SH, Adam JM, Thornalley PJ. Disturbance of B-vitamin status in people with type 2 diabetes in Indonesia-link to renal status, glycemic control and vascular inflammation. Diabetes
Res Clin Pract2012;95: 415-24. doi: 10.1016/j.diabres.2011.10.042.

37. Chetyrkin SV, Mathis ME, Ham AJ, et al. Propagation of protein glycation damage involves modification of tryptophan residues via reactive oxygen species: inhibition by pyridoxamine. Free Radic Biol Med. 2008 ; 1;44(7):1276-85. Life Extension Magazine October 2008

38. Chetyrkin S, Mathis M, Hayes McDonald W, Shackelford X, Hudson B, Voziyan P. Pyridoxamine protects protein backbone from oxidative fragmentation. Biochem Biophys Res Commun 2011;411:574-9. doi: 10.1016/j.bbrc.2011.06.188.

39. Forbes J.M. , Fukami K., Cooper M. E. Diabetic Nephropathy: Where Hemodynamics Meets Metabolism. Exp Clin Endocrinol Diabetes2007; 00:1 - 16. DOI: $10.1055 / \mathrm{s}-2007-949721$

40. Vivian Soetikno, Wawaimuli Arozal, Melva Louisa, and Rianto Setiabudy New Insight into the Molecular Drug Target of Diabetic Nephropathy International Journal of Endocrinology; Volume 2014 (2014), Article ID 968681, 9 pages. $\underline{\text { DOI: }}$ $\underline{10.1155 / 2014 / 968681}$ 